\title{
Insight into the Therapeutic-Switching of Antimalarial Drugs Chloroquine and Hydroxychloroquine for the Pharmacotherapy of COVID-19; A Mini-Review
}

\author{
Zainab Bahardeen* \\ Department of Biomedical Sciences, BMS School of Science, Sri Lanka \\ *Corresponding author: Zainab Bahardeen, Department of Biomedical Sciences, BMS School of Science, 591, Galle Road, \\ Colombo 00600, Sri Lanka
}

\begin{tabular}{|c|c|}
\hline ARTICLE INFO & ABSTRACT \\
\hline Received: & COVID-19, a respiratory tract infection caused by SARS-CoV-2, has evolved into a \\
\hline Published: 慧 May 05, 2020 & $\begin{array}{l}\text { global pandemic. Given the expeditious transmission within a short timeframe, rapidly } \\
\text { escalating patient numbers and deaths calls for the urgency of a potential curative }\end{array}$ \\
\hline $\begin{array}{l}\text { itation: Zainab Bahardeen. Insight into } \\
\text { he Therapeutic-Switching of Antimalarial } \\
\text { Prugs Chloroquine and Hydroxychloro- } \\
\text { quine for the Pharmacotherapy of COV- } \\
\text { D-19; A Mini-Review. Biomed J Sci \& Tech } \\
\text { Res 27(3)-2020. BJSTR. MS.ID.004501. }\end{array}$ & $\begin{array}{l}\text { therapy. Despite the proposed newly emergenttargeted therapies, therapeutic switching } \\
\text { of existing drugs involves potential benefits of, renown safety and pharmacokinetic } \\
\text { profiles, comparatively low production cost and large-scale accessibility. Based on } \\
\text { evidence from an extensive literature survey, the antimalarial drugs Chloroquine (CQ) } \\
\text { and Hydroxychloroquine (HCQ) showed prospective potential to be therapeutically } \\
\text { switched for the treatment of COVID-19. In vitro and clinical studies conducted thus } \\
\text { far, have reported effective anti-SARS-CoV-2 activity of CQ and HCQ, whereas rationale }\end{array}$ \\
\hline $\begin{array}{l}\text { Keywords: Therapeutic-Switching; Chlo- } \\
\text { roquine; Hydroxychloroquine; COVID-19; } \\
\text { SARS-CoV-2 Infection }\end{array}$ & $\begin{array}{l}\text { for the viral inhibition has been postulated. Considering the limitations of the surveyed } \\
\text { studies, evidence from more research is required to further reinforce the therapeutic } \\
\text { potential of CQ and HCQ against COVID-19, whereas comparative studies are required } \\
\text { to investigate the most potent inhibitor of SARS-CoV-2, out of the two drugs of interest. } \\
\text { Simultaneously, studies focused on suggested research recommendations should } \\
\text { be steered in order to ultimately discover and design the most effective therapeutic } \\
\text { regimen involving CQ/HCQ, that may hopefully present a potential solution to the } \\
\text { prevailing deleterious global pandemic. }\end{array}$ \\
\hline
\end{tabular}

\section{Introduction to COVID-19}

Coronavirus disease 2019 (COVID-19) that is currently the cynosure of concern in the global arena, is an infectious respiratory disease caused by a newly emergent strain of betacoronavirus. Notably, two SARS-like coronaviruses that have been responsible for two previous global pandemics, belong to two subgenera of betacoronaviruses, namely; SARS-COV-1 (causative agent of the Severe Acute Respiratory Syndrome (SARS) outbreak in 2002 and 2003 in Guangdong Province, China) of the subgenous Sarbecovirus [1-6], and MERS-CoV (causative agent of the Middle Eastern Respiratory Syndrome (MERS) outbreak of 2012 in Middle East) of the subgenous Merbecovirus [7]. According to phylogenetic findings [1], the novel coronavirus shares identical nucleotide sequences with other SARS-like coronaviruses and is of zoonotic origin. Consequently, the novel strain was named as SARS-CoV-2 (2) by the Coronaviridae Study Group (CSG) of the International
Committee on Taxonomy of Viruses. Despite the genetic similarities, SARS-CoV-2 is reportedly more virulent than both SARS-CoV-1 and MERS-CoV, as individuals can transmit SARS-CoV-2 even when asymptomatic or presymptomatic $[8,9]$.

Reportedly, the first case of COVID-19 was of a 55-year-old resident of Hubei, China, on 17 November 2019 [4], whereas the initial mass breakout occurred in Wuhan, China, during December 2019 [3]. In view of epidemiological studies [10,11], as of 31 January 2020, SARS-CoV-2 had spread to 19 countries, causing11 791 COVID-19 positive cases while reporting 213 deaths. Accordingly, the World Health Organization (WHO) declared it a Public Health Emergency of International Concern [12] on 30 January 2020. As of 1 April 2020, statistics rapidly escalated, resulting in 823626 confirmed cases and 40598 deaths reported worldwide due to COVID 19 [13]. Despite the rapid transmission 
that result in increasing numbers, clinical management of patients had become more difficult as approximately $14 \%$ of positive cases reportedly required hospitalization and oxygen support, whereas about $5 \%$ were in need of treatment under intensive care units [3] Nevertheless, apart from the majority that presented with mild to moderate illness free of comorbidities, severe cases reported complications with Acute Respiratory Distress Syndrome (ARDS), septic shock, sepsis, renal and cardiac failure [14].

Alarmingly, despite aforementioned complexities and rising concerns, absence of an effective therapy for COVID-19 remained a global concern. Correspondingly, more than 80 clinical trials [15] were initiated by the Chinese government and researchers all over the world, in order to evaluate the therapeutic potential of; experimental drug and vaccine candidates, United States Food and Drug Administration (FDA)-approved antiviral drugs and Chinese herbal compounds, aiming at discovering an effective therapy for COVID-19. Nevertheless, researchers and pharmaceutical companies initiated focusing on specific SARS-CoV-2 targeted therapies such as vaccines, monoclonal antibodies, oligonucleotidebased therapies, peptides, interferon therapies and small-molecule drugs. However, though such targeted approaches are seemingly explicit and effective, a prolonged time-frame is required for the development process. Therefore, given the urgency of managing the prevalent and uprising COVID-19 pandemic, repurposing of existing Broad-Spectrum Antiviral Agents (BSAA) and antiviral drugs presents a potentially practicable solution to this end.

\section{Therapeutic Switching of Drugs as a Prospective Curative Approach}

Therapeutic switching of drugs, also known as drugrepurposing, reprofiling, repositioning, or redirecting can be defined as the process of investigating existing drugs for a novel therapeutic purpose, other than the originally intended disease [16]. It involves the advantages of readily accessible synthetic details, known safety profiles and known pharmacokinetic properties. Hence, via therapeutic switching of an existing drug associates a significantly reduced cost of development and timeline to reach the market, in contrast to the launch of an experimental drug. Nevertheless, repurposed drugs associate the convenience of procurement as existing pharmaceutical companies are already equipped to carry out the manufacturing and delivery. Additionally, therapeutic switching includes substantial potential for translational opportunities and higher probability of discovering novel classes of drugs [17]. In view of research pertaining drug reposition conducted thus far, majority of studies suggest remdesivir $[18,19]$, chloroquine (CQ) [18] and hydroxychloroquine (HCQ) [20] as potential candidates that show inhibitory effect against SARS$\mathrm{CoV}-2$, both in vitro as well as in vivo. However, as remdesivir is yet an experimental drug it involves the limitations of; unknown safety profile, high production cost and unavailability of timely large-scale production to meet the current needs.
Alternately, both CQ and HCQ offer prospective potential. Particularly, the FDA designated HCQ for off-label, compassionate use for treating COVID-19 on March 28, 2020 [21], whereas the WHO added the drug to its large global SOLIDARITY trial [22]. Moreover, on April 3, 2020, the Daily Mail UK reported that, in an international poll involving 6200 doctors from 30 nations, majority had voted in favor of antimalarial drugs CQ and HCQ to be effective against COVID-19 [23]. In accordance with this global consensus, the mini-review at hand aims to provide an overview of the mechanism of antiviral action of the two drugs of interest and the possible rationale for their use in the pharmacotherapy of COVID-19. Furthermore, concerned by the absence of a review that collectively summarizes the in vitro and clinical studies on effectiveness CQ and HCQ in COVID-19 therapy, this mini-review provides an updated synopsis of literature published till date, since the outbreak of COVID-19. Thereby, the work at hand intends to enable researchers to discover study areas that require focus and encourage further research, literature reviews and novel opinions regarding the topic at hand.

\section{Potential of Chloroquine and Hydroxychloroquine as a Therapeutic Utility Against COVID-19}

\section{Demonstrated Effectiveness, Rationale and Mechanism of Action of Chloroquine and Hydroxychloroquine as Antimalarial Agents, Disease-Modifying Anti-Rheumatic Drugs and antiviral Agents.}

CQ is a 9-aminoquinoline that was originally used as prophylactic and curative treatment for malaria, whereas HCQ is a metabolite of chloroquine with higher solubility and reduced toxicity [24]. In addition to antimalarial therapy, CQ and HCQ are utilized in clinical settings as disease-modifying anti-rheumatic drugs (DMARDs) for the treatment of autoimmune diseases such as rheumatic arthritis [25], systemic lupus erythematosus [26-29], antiphospholipid syndrome [30] and primary Sjögren syndrome [31,32]. Significantly, both the agents have reported equal effectiveness as antimalarials as well as DMARDS, despite the slight difference in pharmacological properties. Considering their mechanisms of action, CQ and HCQ function as weak bases and favorably accumulate within intracellular compartments [26], thereby triggering numerous downstream cellular activities that offer therapeutic utilities for various diseases. In case of malaria, CQ is postulated to concentrate within the food vacuole of Plasmodium falciparum and interfere with the conversion of heme to hemozoin, thus, causing death to the parasite by heme-induced toxicity [33].

With regard to autoimmune diseases, CQ has been studied to execute an array of immunomodulatory effects via the inhibition of; lymphocytic proliferation, antigen presentation in dendritic cells, lysosomal enzyme release and release of reactive oxygen species from macrophages [34,35]. More recently, promising antiviral activity of CQ and HCQ have been studied. The antiviral effect is primarily elucidated as a result of increase of the 
endosomal and lysosomal $\mathrm{pH}$ by $\mathrm{CQ}$, which in turn impairs the viral release from the respective compartment, as the release of the virus requires a low $\mathrm{pH}$ [36]. Subsequently, the release of the viral genetic material and subsequent replication gets inhibited. Citing research findings by Savarino et al. [37], antiviral activity against HIV-1 and HIV-2 have been studied, wherein CQ and HCQ have shown post-integrational inhibition of newly produced viral envelope glycoproteins. Furthermore, Ooi et al. [38] have demonstrated potential in vitro inhibitory effect of CQ against influenza AH1N1 and influenza AH3N2. Reportedly, Mizui et al. [39] have studied the in vitro inhibition of viral replication by CQ in hepatitis C-transfected Huh-7 cells.

Nevertheless, Xue et al. [40] have shown that CQ promoted the intracellular transport of zinc and the resultant zinc concentration potentially inhibit the replication of Hepatitis- E virus, in vitro. Interestingly, Kaushik, et al. [41] report that the inhibition of viral replication had occurred via inhibition of viral RNA-dependent RNA-polymerase, a molecule used by SARS-CoV-2 and other coronaviruses for viral replication. Therefore, in collective view of evidence from literature that suggests substantial antiviral potential of CQ and HCQ, their potential for therapy against coronaviruses came into light. In a study to investigate the effect of CQ on cellular uptake of nanoparticles [42], a mechanism for the possible antiSARS-CoV-2 action of CQ was postulated, as SARS-CoV-2 falls within the same size range $(60-140 \mathrm{~nm})$ and shape (spherical) [42] as commonly studied synthetic nanoparticles $[43,44]$. The postulated mechanism suggests that CQ may inhibit the endosomal acidification of host cell, whereas the resultant low endosomal $\mathrm{pH}$ will not favor the cleavage of spike protein in the surface of SARSCoV-2 virion. This interference to the cleavage is deduced to inhibit the conformational change in the spike protein upon cleavage, which is necessary for the fusion of viral envelope and endosomal membrane (45). Eventually, inhibition of the release of viral genetic material into the host cell occurs.

\section{In vitro and Clinical Studies on Anti-SARS-CoV-2 Activity of Chloroquine and Hydroxychloroquine}

Considering the seemingly prospective therapeutic potential of CQ and HCQ against SARS-CoV-2, both in vitro and clinical studies had been carried out in order to find potential evidence supporting the claim. Details regarding such trials conducted till date have been summarized in Table 1, whereas of many other Chinese clinical trials such as ChiCTR2000029939, ChiCTR2000029935, ChiCTR2000029935, ChiCTR2000029898, ChiCTR2000029868, ChiCTR2000029803, ChiCTR2000029760, ChiCTR2000029740, ChiCTR2000029609,ChiCTR2000029559and ChiCTR2000029542, some are yet recruiting, some are underway of research, whereas in the rest the findings are yet to be revealed. In view of the tabulated findings, these studies include the limitations of small study populations, studies being poorly controlled or uncontrolled. Therefore, evidence from studies that have overcome these limitations are required in order to arrive at a specific conclusion. Notably, some of the tabulated studies report contraindications of CQ and HCQ. Generally, considering pharmacovigilance studies, CQ and HCQ have upheld a fair safety record [52] as they do not associate risks of infectious complications, in contrast to immunosuppressants such as methotrexate and leflunomide [53].

Table 1: Summarized details of in vitro and clinical trials on chloroquine and hydroxychloroquine for the treatment of COVID-19.

\begin{tabular}{|c|c|c|c|c|}
\hline \multirow{2}{*}{$\begin{array}{l}\text { Drug/ Therapeutic } \\
\text { agent }\end{array}$} & \multicolumn{4}{|c|}{ Experimental findings } \\
\hline & Study group & Study type & Experience & Side effects \\
\hline \multirow[t]{2}{*}{ Chloroquine } & Wang, et al. [18] & In vitro & $\begin{array}{l}\text { CQ-treated SARS-COV-2-infected Vero6 cells showed potent } \\
\text { toxicity with an } \mathrm{EC}_{90} \text { value of } 6.90 \mu \mathrm{M}\end{array}$ & \\
\hline & $\begin{array}{l}\text { Chinese clinical trials } \\
\text { (Cited by Gao, et al.) } \\
\text { [46] }\end{array}$ & Clinical & $\begin{array}{c}\text { Out of the recruited patients, in more than } 100 \text {, chloroquine } \\
\text { phosphate has effectively inhibited the exacerbation of } \\
\text { pneumonia and improved lung imaging findings, while } \\
\text { promoting a virus negative conversion and shortening the } \\
\text { disease course. }\end{array}$ & $\begin{array}{l}\text { No severe adverse } \\
\text { effects were observed }\end{array}$ \\
\hline \multirow[t]{6}{*}{$\begin{array}{l}\text { Hydroxychloroquine } \\
\text { (HCQ) }\end{array}$} & Yao, et al. [47] & In vitro & $\begin{array}{l}\text { HCQ showed potent activity }(\mathrm{EC} 50=0.72 \mu \mathrm{M}) \text { in SARS-CoV-2 } \\
\text { infected Vero cells }\end{array}$ & \\
\hline & Liu, et al. [48] & In vitro & $\begin{array}{l}\text { CCK-8 assays reported potent cytotoxicity in HCQ-treated } \\
\text { VeroE6 cells }\end{array}$ & \\
\hline & $\begin{array}{l}\text { Jun, et al., Shanghai } \\
\text { Public Health Clinical } \\
\text { Center [49] }\end{array}$ & $\begin{array}{l}\text { Clinical - } \\
\text { Phase } 3\end{array}$ & $\begin{array}{c}\text { Better prognosis in HCQ group, compared to the group } \\
\text { treated with conventional drugs, in a cohort of } 30 \text { COVID-19 } \\
\text { treatment-naïve patients }\end{array}$ & $\begin{array}{l}\text { Transient Diarrhoea and } \\
\text { abnormal liver function }\end{array}$ \\
\hline & Zhang, et al. [50] & $\begin{array}{l}\text { Clinical- } \\
\text { Phase } 4\end{array}$ & $\begin{array}{c}\text { Short-term efficacy of HCQ in relieving symptoms, reversal } \\
\text { of severity rate and shortening disease duration of } 50 \\
\text { patients }\end{array}$ & $\begin{array}{l}\text { Mild rash and slight } \\
\text { headache }\end{array}$ \\
\hline & Gautret, et al. [20] & Clinical & $\begin{array}{c}\text { In a cohort of } 20 \text { patients, HCQ showed viral clearance } \\
\text { within } 6 \text { days-post inclusion, whereas its effect was } \\
\text { reinforced by azithromycin }\end{array}$ & \\
\hline & Chen, et al. [51] & Clinical & $\begin{array}{c}\text { Out of } 62 \text { patients, } 31 \text { were treated with HCQ and } \\
\text { significantly reported short duration for remission and } \\
\text { improved pneumonia. }\end{array}$ & Mild adverse reactions \\
\hline
\end{tabular}


However, considering patient diversity, use of CQ and HCQ has reported gastrointestinal adverse effects such as diarrhea and vomiting in some clinical settings [54]. In case of long term exposure, CQ has reported serious side effects such as retinopathy, bull's eye maculopathy and cardiomyopathies [55], whereas HCQ has been studied to cause retinopathy only in case of long term (more than 5 years) use and when exceeded the prescribed dosage. Moreover, CQ has reported fetal defects when administered during pregnancy and toxicities; when administered to the elderly or when exceeded the prescribed dosage. Contrastingly, as HCQ has reportedly lower accumulation rate in tissues, it does not associate such severe adverse effects and thus is considered safe to be administered during pregnancy [56]. Therefore, CQ can be suggested for use in general SARS-CoV-2 infected patient populations whereas HCQ can be suggested for the use in infected pregnant population, children and elderly. Nevertheless, further pharmacovigilance research and comparative studies on safety of CQ and HCQ in SARS-CoV-2 infection are required to evaluate the suggested superior safety profiles of HCQ.

\section{Future Research Recommendations}

Interestingly, a study conducted by Gautret et al. [20] had demonstrated that effective viral elimination was achieved significantly when azithromycin was co-administered with HCQ. Subsequently, it was deduced that more effective clinical management can be achieved in case of combination therapy. Therefore, studies on adjunctive therapy involving the addition of antibiotics to the CQ/HCQ monotherapy, should be encouraged. Prospectively, treatment regimen can be designed as drug cocktails that comprise of antibiotics, antioxidants and immunomodulators, in addition to CQ/HCQ, for more effective and rapid clinical remission. As another strategy to further effectuate the drug action, change of the route of administration can be considered, where the drugs can be designed to be administrated nasally instead of orally, which will increase the bioavailability of drugs in the respiratory system. Therefore, research on formulating CQ and HCQ in the form of inhalers can be suggested as it may accelerate and effectuate the process of viral elimination from the respiratory system, which may prospectively improve patient symptoms and prevent the progress into critical stages or fatality.

Nevertheless, considering pharmacokinetics, research on drug distribution, availability and duration of action needs to be evaluated. Findings by Keyaearts et al. [57] that show the successful treatment of a lethal HCoV-OC43 infection in newborn C57BL/6 mice subsequent to administration of CQ transplacentally or through maternal milk, had shown a significant increase of survival rates in a dose-dependent manner. Therefore, further research on investigating the dose-dependent therapeutic effect and evaluating the exact prescriptible therapeutic concentration needs to be evaluated. Moreover, CQ has been shown to inhibit SARS-CoV in vitro, even when administered after viral uptake [58]. This signifies the possible prophylactic effect of CQ against SARS-COV-2 infection, apart from its studied therapeutic effect. Hence, further research should be steered on the rationale for the suggested prophylactic potential of CQ and HCQ and the exact prescriptible prophylactic dosage.

\section{Conclusion}

Overall, therapeutic-switching of CQ and HCQ has offered effective therapeutic utility and has demonstrated substantial potential against SARS-CoV-2 infection in both in vitro and clinical studies conducted thus far. However, considering the limitations of those studies, evidence from further studies of more controlled nature and involving large test population is required in order to arrive at an exact conclusion. Studies on adjunctive therapy, formulation of CQ/HCQ for nasal administration and determination of exact prescriptible therapeutic and prophylactic concentration of CQ/HCQ have been proposed as future avenues for research. In conclusion, further comparative studies on CQ and HCQ against SARS-CoV-2 are required to investigate which has higher therapeutic activity in COVID-19.

\section{References}

1. Zhou P, Yang X, Wang X, Hu B, Zhang L, et al. (2020) A pneumonia outbreak associated with a new coronavirus of probable bat origin. Nature 579(7798): 270-273.

2. Alexander E Gorbalenya, Susan Baker, Ralph Baric, Raoul J de Groot (2020) The species severe acute respiratory syndrome-related coronavirus: classifying 2019-nCoV and naming it SARS-CoV-2. Nat Microbiol 5(5): 534-544.

3. (2020) The Novel Coronavirus Pneumonia Emergency Response Epidemiology Team. The epidemiological characteristics of an outbreak of 2019 novel coronavirus diseases (COVID-19) - China. China CDC Weekly 41(2): 145-151.

4. (2019) Wuhan Municipal Health Commission. Report of clustering pneumonia of unknown etiology in Wuhan City, China.

5. Zhong NS, Zheng BJ, Li YM, Poon, Xie ZH, et al. (2003) Epidemiology and cause of severe acute respiratory syndrome (SARS) in Guangdong, People's Republic of China in February 2003. Lancet 362 (9393): 13531358.

6. Drosten C, Günther S, Preiser W, van der Werf S, Brodt HR, et al. (2003) Identification of a novel coronavirus in patients with severe acute respiratory syndrome. N Engl J Med 348(20): 1967-1976.

7. Zaki AM, van Boheemen S, Bestebroer TM, Osterhaus AD, Fouchier RA (2012) Isolation of a novel coronavirus from a man with pneumonia in Saudi Arabia. N Engl J Med 367(19): 1814-1820.

8. Bai Y, Yao L, Wei T, Tian F, Jin DY, et al. (2020) Presumed asymptomatic carrier transmission of COVID-19. JAMA 323(14): 1406-1407.

9. Wei WE, Li Z, Chiew CJ, Yong SE, Toh MP, Lee VJ (2020) Presymptomatic transmission of SARS-CoV-2 - Singapore, January 23 - March 16, 2020. Morb Mortal Wkly Rep 69(14): 411-415.

10. Adhikari S, Meng S, Wu Y, Mao YP, Ye RX, et al. (2020) Epidemiology, causes, clinical manifestation and diagnosis, prevention and control of coronavirus disease (COVID-19) during the early outbreak period: a scoping review. Infect Dis Poverty 9(1): 29.

11. Khachfe HH, Chahrour M, Sammouri J, Salhab HA, Makki EB, et al. (2020) An epidemiological study on COVID-19: a rapidly spreading disease. Cureus 12(3): e7313. 
12. (2005) World Health Organization. Statement on the second meeting of the International Health Regulations (2005) Emergency Committee regarding the outbreak of novel coronavirus (2019-nCoV), Geneva, Switzerland.

13. (2019) World Health Organization. Coronavirus disease 2019 (COVID-19) Situation Report- 72.

14. Yang X, Yu Y, Xu J, Shu H, Xia J, et al. (2020) Clinical course and outcomes of critically ill patients with SARS-CoV-2 pneumonia in Wuhan, China: a single-centered, retrospective, observational study. Lancet Respir Med.

15. Maxmen A (2020) Slew of trials launch to test coronavirus treatments in China. Nature 578: 347-348.

16. Mercorelli B, Palù G, Loregian A (2018) drug repurposing for viral infectious diseases: how far are we. Trends Microbiol 26(10): 865-876.

17. Pushpakom S, Iorio F, Eyers PA, Escott KJ, Hopper S, et al. (2018) Drug repurposing: progress, challenges and recommendations. Nat Rev Drug Discov 18(1): 41-58.

18. Wang M, Cao R, Zhang L, Yang X, Liu J, et al. (2020) Remdesivir and chloroquine effectively inhibit the recently emerged novel coronavirus (2019-nCoV) in vitro. Cell Res 30(3): 269-271.

19. Holshue ML, DeBolt C, Lindquist S, Lofy KH, Wiesman J, et al. (2020) First case of 2019 novel coronavirus in the United States. N Eng J Med 382(10): 929-936.

20. Gautret P, Lagier JC, Parola P, Hoang VT, Meddeb L, et al. (2020) Hydroxychloroquine and azithromycin as a treatment of COVID-19: results of an open-label non-randomized clinical trial. Int J Antimicr Agents 105949.

21. (2019) United States Food and Drug Administration. FDA request for emergency use authorization for use of chloroquine phosphate or hydroxychloroquine sulfate supplied from the strategic national stockpile for treatment of 2019 coronavirus disease.

22. (2020) World Health Organization. 'Solidarity' trials for COVID-19 treatments.

23. DailyMail Online. Trump-backed anti Malaria drug hydroxychloroquine is the most effective coronavirus treatment currently available, finds international poll of 2,000 doctors.

24. Agrawal P (2015) Advantages and challenges in drug re-profiling. J Pharmacovigil s2(e002).

25. Browning DJ (2014) Pharmacology of chloroquine and hydroxychloroquine, p. 35-63.

26. Smolen JS, Landewé R, Breedveld FC, Buch M, Burmester G, et al. (2014) EULAR recommendations for the management of rheumatoid arthritis with synthetic and biological disease-modifying antirheumatic drugs: 2013 update. Ann Rheum Dis 73(3): 492-509.

27. Fanouriakis A, Kostopoulou M, Alunno A, Aringer M, Bajema I, et al. (2019) 2019 update of the EULAR recommendations for the management of systemic lupus erythematosus. Ann Rheum Dis 78(6): 736-745.

28. Pons Estel BA, Bonfa E, Soriano ER, Cardiel MH, Izcovich A, et al. (2018) First Latin American clinical practice guidelines for the treatment of systemic lupus erythematosus: Latin American Group for the Study of Lupus (GLADEL, Grupo Latino Americano de Estudio del Lupus)-PanAmerican League of Associations of Rheumatology (PANLAR). Ann Rheum Dis 77(11): 1549-1557.

29. Gordon C, Amissah Arthur MB, Gayed M, Brown S, Bruce IN5, et al. (2018) The British Society for Rheumatology guideline for the management of systemic lupus erythematosus in adults. Rheumatology (Oxford) 57(1) e1-e45.

30. Tektonidou MG, Andreoli L, Limper M, Amoura Z, Cervera R, et al. (2019) EULAR recommendations for the management of antiphospholipid syndrome in adults. Ann Rheum Dis 78(10): 1296-1304.
31. Brito Zeron P, Ramos Casals M, EULAR SS Task Force Group (2014) Advances in the understanding and treatment of systemic complications in Sjogren's syndrome. Curr Opin Rheumatol 26(5): 520-527.

32. Vivino FB, Carsons SE, Foulks G, Daniels TE, Parke A, et al. (2016) New treatment guidelines for Sjogren's disease. Rheum Dis Clin North Am 42(3): 531-551.

33. Misbahi H (2013) Malaria: mode of action of chloroquine and mechanism of chloroquine resistance. Journal de Pharmacie Clinique 32(3): 143153.

34. Andrea S, Luisa G, Hou Chu C, Davide S, Fabio M (2001) Anti-HIV effects of chloroquine: mechanisms of inhibition and spectrum of activity. AIDS 15(17): 2221-2229

35. Thomé R, Moraes AS, Bombeiro AL, Farias AS, Francelin C, et al. (2013) Chloroquine treatment enhances regulatory $\mathrm{T}$ cells and reduces the severity of experimental autoimmune encephalomyelitis. PLoS One 8(6): e65913.

36. Al Bari MAA (2017) Targeting endosomal acidification by chloroquine analogs as a promising strategy for the treatment of emerging viral diseases. Pharmacol Res Perspect 5(1): e00293.

37. Savarino A, de Trani L, Donatelli I, Cauda R, Cassone A (2006) New insights into the antiviral effects of chloroquine. Lancet Infect Dis 6(2): 67-69.

38. Ooi EE, Chew JS, Loh JP, Chua RC (2006) In vitro inhibition of human influenza A virus replication by chloroquine. Virol J 3: 39.

39. Mizui T, Yamashina S, Tanida I, Takei Y, Ueno T, et al (2010) Inhibition of hepatitis $\mathrm{C}$ virus replication by chloroquine targeting virus-associated autophagy. J Gastroenterol 45(2): 195-203.

40. Xue J, Moyer A, Peng B, Wu J, Hannafon BN, et al. (2014) Chloroquine is a zinc ionophore. PLoS One 9(10): e109180.

41. Kaushik N, Subramani C, Anang S, Muthumohan R, Shalimar, et al. (2017) Zinc salts block Hepatitis E virus replication by inhibiting the activity of viral RNA-dependent RNA polymerase. J Virol 91(21): e00754-17.

42. Hu TY, Frieman M, Wolfram J (2020) Insights from nanomedicine into chloroquine efficacy against COVID-19. Nat Nanotechnol 15(4): 247279.

43. Zhu N, Zhang D, Wang W, Li X, Yang B, et al. (2020) A novel coronavirus from patients with pneumonia in China, 2019. N Engl J Med 382(8): 727 733.

44. Wolfram J, Ferrari M (2019) Clinical cancer nanomedicine. Nano Today 25: 85-89.

45. Gentile E, Cilurzo F, Marzio LD, Carafa M, Ventura CA, et al. (2013) Liposomal chemotherapeutics. Future Oncol 9(12): 1849-1859.

46. Gao J, Tian Z, Yang X (2020) Breakthrough: chloroquine phosphate has shown apparent efficacy in treatment of COVID-19 associated pneumonia in clinical studies. BioSci Trends 14(1): 72-73.

47. Yao X, Ye F, Zhang M, Cui C, Huang B, et al. (2020) In vitro antiviral activity and projection of optimized dosing design of bydroxychloroquine for the treatment of severe acute respiratory syndrome coronavirus 2 (SARSCoV-2). Clin Infect Dis: ciaa237.

48. Liu J, Cao R, Xu M, Wang X, Zhang H, et al. (2020) Hydroxychloroquine, less toxic derivative of chloroquine, is effective in inhibiting SARS-CoV-2 infection in vitro. Cell Discov 6: 16

49. Jun C, Danping L, Li L, Ping L, Quingnian X, et al. (2020) A pilot study of hydroxychloroquine in treatment of patients with common coronavirus disease-19 (COVID-19). J Zhejiang Univ (Med Sci) 49(1): 0-0.

50.Zhang Z. Wuhan trial. Available from: https://s.wsj.net/public/ resources/documents/Zhan-Wuhan-Trial.pdf?mod=article_inline

51. Chen Z, Hu J, Zhang Z, Jiang S, Han S, et al. (2020) Efficacy of hydroxychloroquine in patients with COVID-19: results of a randomized clinical trial. medRxiv: 1-11. 
52. Abdulaziz N, Shah AR, McCune WJ (2018) Hydroxychloroquine: balancing the need to maintain therapeutic levels with ocular safety: an update. Curr Opin Rheumatol 30(3): 249-255.

53. Ruiz Irastorza G, Olivares N, Ruiz Arruza I, Martinez Berriotxoa A, Egurbide MV, et al. (2009) Predictors of major infections in systemic lupus erythematosus. Arthritis Res Ther 11(4): R109.

54. Srinivasa A, Tosounidou S, Gordon C (2017) Increased incidence of gastrointestinal side effects in patients taking hydroxychloroquine: a brand-related issue? J Rheumatol 44(3): 398.

55. Schrezenmeier E, Dorner T (2020) Mechanisms of action of hydroxychloroquine and chloroquine: implications for rheumatology. Nat Rev Rheumatol 16(3): 155-166.

ISSN: 2574-1241

DOI: $10.26717 /$ BJSTR.2020.27.004501

Zainab Bahardeen. Biomed J Sci \& Tech Res

CC) (i) This work is licensed under Creative Commons Attribution 4.0 License

Submission Link: https://biomedres.us/submit-manuscript.php
56. Mokhtar M (2012) Comparative study between the toxic effect of chloroquine and hydroxychloroquine onadult albino rats' testis.

57. Keyaerts E, Li S, Vijgen L, Rysman E, Verbeeck J, et al. (2009) Antiviral activity of chloroquine against human coronavirus OC43 infection in newborn mice. Antimicrob Agents Chemother 53(8): 3416-3421.

58. Vincent MJ, Bergeron E, Benjannet S, Erickson BR, Rollin PE, et al. (2005) Chloroquine is a potent inhibitor of SARS coronavirus infection and spread. Virol J 2: 69 .

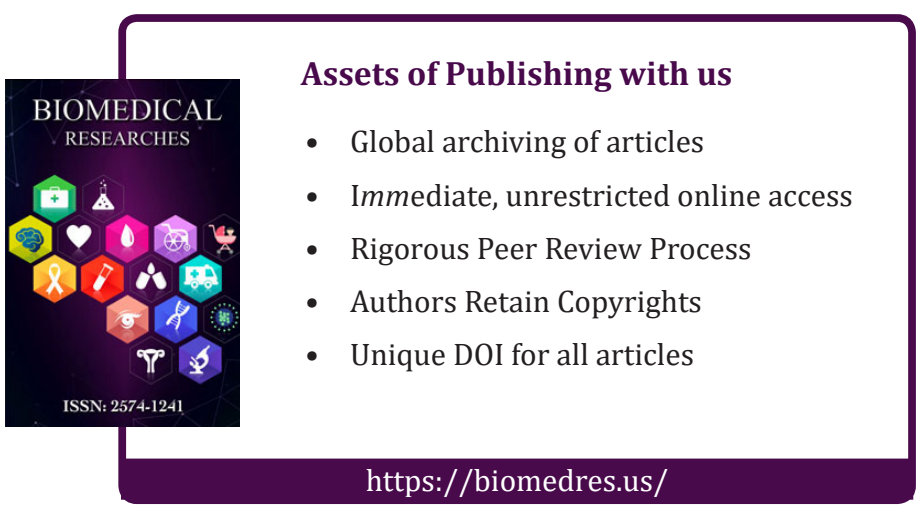

